\title{
EDUKASI MANUAL MATERIAL HANDLING UNTUK PENCEGAHAN MUSCULOSKELETAL DISORDERS PADA PEKERJA INDUSTRI KATERING DI DESA BANGUNTAPAN, BANTUL
}

\author{
Helfi Agustin'), Machfudz Eko Arianto²), Sayid M. Idrus ${ }^{3)}$, Adella Fajrianty' ${ }^{4)}$, Nurrohmah5), \\ Meilana Nawang S. ${ }^{6}$, Ninda Yudhistira ${ }^{7)}$, Aqilla Padya P..$^{8}$ \\ Fakultas Kesehatan Masyarakat - Universitas Ahmad Dahlan \\ Jalan. Prof. Dr. Soepomo, Warungboto. Umbulharjo, Yogyakarta, \\ D.I. Yogyakarta, Indonesia \\ *Corresponding Email: helfi.agustin@ikm.uad.ac.id
}

\begin{abstract}
ABSTRAK
Salah satu masalah keselamatan dan kesehatan kerja yang banyak terjadi di katering adalah terkait dengan ergonomi. Aktivitas mengangkat, menurunkan, mendorong, menarik dan membawa beban, jika tidak dilakukan dengan tepat atau penggunaan alat yang tidak ergonomis, maka kemungkinan akan menimbulkan risiko cedera pada pekerja. Proses kerja di katering mulai dari persiapan bahan yakni mengangkat bahan makanan dari pasar ke tempat penyimpanan sementara, mengangkat periuk/pot yang berisi makanan dari tungku saat proses memasak, mengangkat makanan siap saji untuk didistribusikan ke pelanggan, jam kerja yang panjang, pekerjaan yang berulang dengan postur tubuh yang sama ketika mempersiapkan bahan makanan, disain dapur dan peralatan yang tidak ergonomis, tempat kerja yang terbatas merupakan faktor risiko utama terjadinya musculoskeletal pada pekerja di usaha katering. Upaya pencegahan penting dilakukan agar pekerja katering tercegah dari Penyakit Akibat Kerja (PAK) khususnya musculoskeletal disorders. Pengabdian kepada masyarakat dilakukan pada pekerja dan pemilik usaha katering di Desa Banguntapan, Kab. Bantul. Berdasarkan community diagnosis, pekerja pada umumnya mengeluhkan pegalpegal. Bertujuan untuk mengedukasi cara mengangkat beban yang ergonomis untuk mencegah musculoskeletal disorders. Metode pelaksanaan adalah dengan penyuluhan langsung dengan media poster. Komunikasi persuasif dilakukan untuk menyampaikan kontribusi penting pihak pengelola dan pekerja dalam menegakkan keselamatan dan kesehatan kerja. Kegiatan penyuluhan ini berjalan dengan baik, pengelola dan para pekerja paham dan dapat mempraktikkan secara langsung cara mengangkat beban dengan benar. Pengabdian kepada masyarakat ini merupakan upaya pemberdayaan masyarakat untuk meningkatkan pengetahuan dan keterampilan dalam mewujudkan konsep lingkungan kerja yang ergonomis.
\end{abstract}

Kata kunci: angkat material secara manual, ergonomi, katering, gangguan otot rangka

\section{ABSTRACT}

One of Occupational safety and health (OSH) problem in catering is related to ergonomics. Lifting, lowering, pushing, pulling and carrying loads, done incorrectly or the use of tools that are not ergonomic, will pose a risk of injury to workers. The working process in catering starts from the preparation of ingredients; food is lifted from the market to temporary storage, then during the cooking process; lifting pots containing food from the stove, after the food is cooked; lifting food that to be distributed to customers affects musculoskeletal. Musculoskeletal risk factors in the catering business are long working hours, repetitive work with the same posture when preparing food, kitchen design, and unergonomic equipment, also limited workplace. Prevention efforts are important to prevent catering workers from Occupational Diseases, especially musculoskeletal disorder. Community service was provided to catering business owners and workers in the village of Banguntapan, Kab. Bantul. Based on community diagnosis, workers generally complain of illness. Aims to give awareness about risk and how to prevent musculoskeletal disorders by lifting weights properly. The method was counselling by poster media. Persuasive communication was carried out to convey the important contribution of all parties in enforcing OSH. Activities were going well, 
managers and workers understood and can practice how to lift weights properly. This community service is an effort to empower people to increase their knowledge and care in realizing an ergonomic work environment concept.

Keyword : Manual material handling, ergonomic, catering, musculoskeletal disorders

\section{Pendahuluan}

Ada dua aspek penting kesehatan masyarakat dalam usaha jasa katering yaitu Hyigiene sanitasi makanan dan Keselamatan dan Kesehatan Kerja (K3). Hygiene sanitasi makanan lebih bersifat perlindungan terhadap konsumen agar makanan yang disediakan aman bagi kesehatan, sedangkan K3 lebih bersifat perlindungan terhadap pekerja katering. Masalah keamananan pangan telah lama menjadi perhatian kesehatan masyarakat, karena berkaitan dengan perlindungan kesehatan konsumen. Akan tetapi masalah kesehatan masyarakat lainnya yang berpotensi terjadi di usaha katering adalah masalah ergonomi (Shankar, Shanmugam, \& Srinivasan, 2015). Beban kerja di katering cukup berat yakni menyiapkan makanan dalam kapasitas besar, mengangkat barang berat dan dalam jumlah yang banyak, dan jam kerja yang panjang. Selain itu selama aktivitas proses menyiapkan makanan, postur tubuh pekerja yang sama dalam waktu lama seperti posisi kepala menunduk pada saat memotong dan mencacah, penggunaan peralatan yang tidak aman dan ergonomis, serta disain tempat kerja yang tidak ergonomis menjadi faktor risiko utama yang menimbulkan musculoskeletal disorders pada pekerja usaha catering (Xu, Cheng, \& Li-tsang, 2013). Upaya pencegahan penting dilakukan agar produktifitas pekerja di katering tidak terganggu.

Masalah ergonomi terkait dengan kesesuaian tubuh dengan peralatan kerja pada saat melakukan aktivitas pekerjaan. Salah satu aktivitas yang sering menimbulkan masalah ergonomi di usaha katering adalah aktivitas mengangkat material (Hospitality and catering Industry Liaison Forum, 2017; TSO London, 2020). Aktivitas pengangkatan material secara manual meliputi berbagai kegiatan termasuk mengangkat, menurunkan, mendorong, menarik dan membawa. Jika salah satu dari kegiatan tersebut tidak dilakukan dengan tepat, maka kemungkinan akan menimbulkan risiko cedera. Pengangkatan material secara manual menyebabkan 3-86\% gangguan otot rangka di tempat kerja (Xu et al., 2013). Termasuk gangguan nyeri dan cedera pada lengan, kaki dan sendi dan cedera regangan berulang dari berbagai jenis pekerjaan.

Keluhan low back pain adalah salah satu dari keluhan musculoskeletal desease. Literatur menunjukkan bahwa terjadi peningkatan prevalensi low back pain kronis sebesar 84\%, yang berlanjut menjadi kronis sebanyak 23 dan 11-12\% mengakibatkan kelainan yang menetap pada otot dan kerangka tubuh (Almoallim, Alwafi, Albazli, Alotaibi, \& Bazuhair, 2014). Low back pain dapat terjadi di banyak tempat kerja, mulai dari perawat (Nurhafizhoh, 2019), nelayan (Wahab, 2019), penjahit konveksi (Wijayanti, Oktafany, Ramadhian, Saftarina, \& Cania, 2019), buruh angkut di pasar tradisional (Abdullah, Susilo, \& Sumekar, 2014; Pratiwi, Widjasena, \& Suroto, 2015), porter (Benynda, 2016), pengemudi (Sekaaram \& Ani, 2017), (Xu et al., 2013), termasuk di katering (Budiman, Nurhayati, \& Sakinah, 2017; Nagasu, Tomita, \& Miyagi, 2007; Shankar et al., 2015; Tomita et al., 2013). Pekerjaan di katering yang banyak menggunakan postur canggung seperti gerakan membungkuk dan memutar, memerlukan kekuatan atau aktivitas yang dilakukan berulang secara berlebihan, waktu lembur berlebihan dan kurang istirahat telah meningkatkan risiko musculoskeletal disorders pada pekerja katering (Budiman et al., 2017; Nagasu et al., 2007; Shankar et al., 2015; Tomita et al., 2013).

Upaya pencegahan musculoskeletal disorders dapat dilakukan dengan cara melakukan prosedur pengangkatan beban yang benar. Oleh sebab itu pelatihan tentang cara mengangkat beban terhadap pekerja katering perlu dilakukan. Pekerja perlu tahu cara bekerja yang aman dan tanpa risiko kesehatan. Pelatihan yang memadai bagi karyawan terkait mengangkat beban adalah tentang: risiko yang terkait dengan manual handling dan tugas berulang - Teknik pengangkatan dan penanganan yang aman; - identifikasi risiko, deteksi dini gejala, menerapkan langkah-langkah pengendalian, dan prosedur pelaporan (Hospitality and catering Industry Liaison Forum, 2017). 
Berdasarkan identifikasi masalah di atas, musculoskeletal disorders dapat diminimalisasi dengan penerapan keselamatan dan kesehatan kerja di lapangan yakni dengan pendekatan pencegahan atau pengurangan risiko. Solusi yang ditawarkan oleh Tim Pengusul guna mengatasi permasalahan mitra adalah sebagai berikut :

1. Penyuluhan tentang faktor risiko manual handling dan upaya pengendalian yang dapat dilakukan. Upaya perubahan perilaku seringkali diawali dengan memberikan penyadaran (awareness) terhadap individu melalui penyuluhan dan pelatihan, berdasarkan pengetahuan yang dimiliki maka akan terbentuk sikap positif dan pada akhirnya individu diharapkan akan membuat keputusan untuk berpraktik atau melakukan tindakan.

2. Pelatihan tentang teknik pengangkatan dan penanganan yang aman untuk pencegahan musculoskeletal disorders pada pekerja katering di Desa Banguntapan, Kec. Banguntapan, Kabupaten Bantul.

Tujuan kegiatan pengabdian kepada masyarakat ini dilakukan untuk mengatasi permasalahan keterbatasan pemahaman anggota pekerja katering mengenai cara mengangkat yang benar dan apa akibatnya terhadap kondisi kesehatan pekerja, serta melatih pekerja cara melakukan pengangkatan yang benar.

\section{Tinjauan Pustaka}

Pemilik usaha wajib melindungi pekerjanya dari masalah kesehatan dan bahaya yang timbul di tempat kerja. Termasuk di dalamnya bahaya yang ditimbulkan oleh karena pengangkatan beban secara manual yang tidak dapat dihindarkan di usaha katering. Manual material handling merupakan aktivitas memindahkan, menggendong suatu beban dengan menggunakan tangan atau kekuatan tubuh, termasuk mengangkat, menurunkan, mendorong, menarik dan membawa (safetysign.co.id, 2018). Jika salah satu dari kegiatan tersebut tidak dilakukan dengan tepat, maka kemungkinan akan menimbulkan risiko cedera. Manual material handling menyebabkan lebih dari sepertiga dari semua cedera di tempat kerja (TSO London, 2020). Ini termasuk musculoskeletal disorders (MSDs atau gotra) yang berhubungan dengan pekerjaan seperti nyeri dan cedera pada lengan, kaki dan sendi dan cedera regangan berulang dari berbagai jenis pekerjaan (Hospitality and catering Industry Liaison Forum, 2017).

Musculoskeletal desease adalah gangguan pada bagian-bagian otot rangka, saraf, urat, sendi, dan tulang rawan yang dirasakan oleh seseorang mulai dari keluhan sangat ringan sampai sangat sakit (Tarwaka, 2014). Studi tentang MSDs pada berbagai jenis industri telah banyak dilakukan dan hasil studi menunjukkan bahwa bagian otot yang sering dikeluhkan adalah otot rangka yang meliputi otot leher, bahu, lengan, tangan, jari, punggung, pinggang dan otot-otot bagian bawah(Shankar et al., 2015; Xu et al., 2013). Diantara keluhan otot rangka tersebut, yang banyak dialami oleh pekerja adalah otot bagian pinggang (low back pain=LBP)(Tomita et al., 2013; Wijayanti et al., 2019). Sementara menurut data National Safety Council sakit punggung merupakan penyakit akibat kerja yang prevalensinya paling tinggi, yaitu $22 \%$ dari 1.700 .000 kasus (Tarwaka, 2004). Secara fisilogis, proses terjadinya musculoskeletal disorders adalah karena pemberian beban kerja yang terlalu berat dengan durasi pembebanan yang panjang sehingga sehingga menimbulkan konstraksi otot maksimum yakni melebihi $20 \%$. Akibatnya peredaran darah ke otot berkurang menurut tingkat kontraksi, dengan berkurangnya peredaran darah maka suplai oksigen ke otot menurun, sehingga proses metabolisme karbohidrat terhambat, akibatnya terjadi penimbunan asam laktat yang menyebabkan timbulnya rasa nyeri otot (Suma'mur, 1982)

Beberapa faktor yang dapat menyebabkan terjadinya keluhan otot rangka yaitu peregangan otot yang berlebihan, aktivitas berulang terus menerus tanpa memperoleh kesempatan otot untuk relaksasi, dan sikap kerja yang tidak alamiah. Sikap kerja yang tidak alamiah menyebabkan posisi bagian-bagian tubuh bergerak menjauhi posisi alamiah. Di Indonesia sikap kerja yang tidak alamiah umumnya terjadi karena ketidaksesuaian peralatan dengan ukuran tubuh orang Indonesia (Tarwaka, 2004). Ditinjau dari aspek biomekanika, semakin jauh posisi bagian tubuh dari pusat gravitasi tubuh 
maka semakin tinggi pula risiko terjadinya keluhan otot rangka (Tarwaka, 2004). Penyebab sekunder musculoskeletal disorders yaitu tekanan, getaran dan suhu (Shankar et al., 2015). Faktor kombinasi yang dapat meningkatkan risiko musculoskeletal disorders adalah usia, jenis kelamin, kebiasaan merokok dan kekuatan fisik, kesegaran jasmani, ukuran tubuh (Shankar et al., 2015). Alat ukur ergonomik sederhana yang dapat digunakan untuk mengetahui hubungan antara tekanan fisik dengan risiko keluhan otot rangka yaitu penggunaan checklist, Nordic Body Map (NBM) dan metode Rapid Entire Body Assessment (REBA) (Tarwaka, 2004). Cara pengukuran dengan NBM dengan melihat dan menganalisis peta tubuh, sehingga dapat diestimasi jenis dan tingkat keluhan otot rangka yang dirasakan oleh pekerja. Cara ini sangat sederhana namun kurang teliti karena mengandung subjektivitas yang tinggi.

Teknik manual material handling banyak melibatkan kerja otot dan tumpuan pada kerja tulang belakang, oleh karena itulah dibutuhkan teknik yang benar. Teknik manual material handling yaitu sebagai berikut: a. membuat perencanaan dengan menilai beban dan menentukan bagaimana menanganinya, sebagai suatu cara untuk menghindari cedera akibat pengerahan tenaga yang berlebih. b. menentukan teknik terbaik dengan menghindari postur membungkuk, memuntir, dan menjangkau yang tidak diperlukan. c. menggenggam objek dengan pegangan yang kuat dan menggunakan seluruh jemari dari kedua tangan dalam mengangkat barang. d. Dorong beban sedekat mungkin dengan badan untuk mencegah stress yang berlebihan di punggung. e. Variasikan penanganan tugas berat dengan yang ringan. f. Periksakan material dari permukaan yang bergigi, sudut yang runcing dan tajam atau licin. g. Menghilangkan minyak, air atau objek yang kotor sebelum mencoba menanganinya ( Hospitality and catering Industry Liaison Forum, 2017). Secara garis besar teknik tersebut adalah sebagai berikut di bawah ini :1) Pegangan terhadap bahan yang diangkat harus tepat. 2) Lengan harus berada sedekat mungkin dengan badan dan dalam posisi lurus. 3) Posisi tulang belakang harus tetap lurus. 4) Dagu segera ditarik setelah kepala bisa ditegakkan. 5) Posisi kaki merenggang untuk membagi momentum dalam posisi mengangkat. 6) Berat badan dimanfaatkan untuk; menarik dan mendorong, sedangkan gaya untuk gerakan dan perimbangan. 7) Beban diusahakan sedekat mungkin terhadap garis vertikal yang melalui pusat gravitasi tubuh (center of gravity) (Tarwaka, 2004).

Pengendalian riesiko manual material handling merupakan suatu proses untuk menghilangkan atau menurunkan faktor risiko yang telah diidentifikasi dan dinilai sebelumnya. Upaya pencegahan dan pengendalian musculoskeletal disorders ada dua yakni dengan rekayasa teknik dan rekayasa manajemen. Rekayasa teknik dilakukan dengan alternatif: penggunaan alat bantu mekanik, mengganti objek kerja menjadi lebih kecil atau lebih mudah untuk dikerjakan, redesain pekerjaan (Tarwaka, 2004). Rekayasa manajemen bertujuan untuk mencegah sikap kerja tidak alamiah dan mengurangi beban kerja yang berlebihan. Rekayasa manajemen dapat dilakukan dengan pengaturan waktu kerja dan istirahat yang seimbang, pengawasan yang intensif terhadap akifitas pengangkatan beban manual misalnya meminimalkan aktivitas angkat-angkut secara manual, mengawasi agar lantai kerja tidak licin, menggunakan alat bantu kerja yang memadai seperti kereta dorong, pengungkit, menggunakan alas apabila harus mengangkat di atas kepala atau bahu, upayakan agar beban angkat tidak melebihi kapasitas angkat pekerja, upayakan untuk menggunakan bahan dan alat yang ringan, wadah/alat angkut dengan kapasitas $<50 \mathrm{~kg}$, upayakan agar ukuran pegangan tangan sesuai dengan lingkar genggam pekerja dan karakteristik pekerjaan, pasang lapisan peredam getaran pada pegangan tangan, upayakan pemeliharaan yang rutin sehingga alat selalu dalam kondisi layak pakai (Tarwaka, 2004).

Rekayasa manajemen untuk pencegahan musculoskeletal disorder juga dapat dilakukan dengan pendidikan dan pelatihan. Edukasi ergonomi terhadap para mahasiswa pendidikan program kedokteran gigi, terbukti menghasilkan perbedaan rata-rata keluhan low back pain sebelum dan setelah dilakukan edukasi (Agusdianti, Sudirman, \& Muliarta, 2017). Edukasi ergonomi juga memberi dampak positif terhadap mahasiswa kedokteran gigi dalam menurunkan keluhan musculoskeletal disorders dan memperbaiki konsistensi postur tubuh. Latihan peregangan juga 
mempengaruhi tingkat keluhan karyawan administrasi di BPOM Bandar Lampung (Tania, 2020). Perbedaan tingkat pengetahuan juga ditemukan pada nelayan sebelum dan sesudah diberi konseling ergonomi (Sholihah, Satria, Alim, \& Fauzia, 2016), edukasi tentang low back pain juga mengembangkan kesadaran urgensi siswa tentang kesehatan melalui posisi duduk yang benar secara ergonomi (Sari, Ismaningsih, Zein, \& Hayati, 2019), pendidikan pasien yang intensif masih efektif menurunkan low back pain tapi tidak bagi pasien yang kronik (AJ et al., 2011), dan ada pengaruh pelatihan sikap manual material handling pada siswa Madrasah dalam membawa peralatan sekolah dengan musculoskeletal desease yang dialami siswa (Rizqiyah, Universitas, \& Malang, 2020).

\section{Metode}

Sasaran kegiatan ini adalah pengelola dan pekerja katering. Pada saat perencanaan program pengabdian kepada masyarakat, pengabdi melakukan analisis situasi. Koordinasi dilakukan dengan pihak Puskesmas Banguntapan III dan pamong Desa Banguntapan untuk mendapatkan gambaran awal mengenai usaha katering yang ada di Desa Banguntapan. Koordinasi dilakukan sejak bulan Januari 2020 bersamaan dengan kegiatan Praktik Belajar Lapangan mahasiswa yang kemudian dijadikan dasar komitmen kegiatan. Community diagnosis dilakukan terhadap lima katering yang berada di Desa Banguntapan, Kabupaten Bantul, yaitu:

\section{Tabel 1. Community Diagnosis Terhadap Lima Katering}

\begin{tabular}{|c|c|c|c|c|}
\hline No. & $\begin{array}{c}\text { Nama } \\
\text { Katering }\end{array}$ & Kategori & Jumlah pekerja & Pelayanan \\
\hline 1 & RI & A3 & $\mathrm{L}=3 \mathrm{P}=5$ & $\begin{array}{l}\text { melayani masyarakat dan menerima pesanan lebih } \\
\text { dari } 600 \text { porsi setiap harinya }\end{array}$ \\
\hline 2 & $\mathrm{~B}$ & A3 & $\mathrm{L}=3 \mathrm{P}=7$ & $\begin{array}{l}\text { melayani masyarakat dan menerima pesanan lebih } \\
\text { dari } 600 \text { porsi setiap harinya }\end{array}$ \\
\hline 3 & M & $\mathrm{B}$ & $\mathrm{L}=7 \mathrm{P}=31$ & melayani Institusi \\
\hline 4 & $\mathrm{~N}$ & A3 & $\mathrm{L}=5 \mathrm{P}=7$ & $\begin{array}{l}\text { melayani masyarakat dan menerima pesanan lebih } \\
\text { dari } 600 \text { porsi setiap harinya }\end{array}$ \\
\hline 5 & SPW & A3 & 60 & $\begin{array}{l}\text { melayani masyarakat dan menerima pesanan lebih } \\
\text { dari } 600 \text { porsi setiap harinya }\end{array}$ \\
\hline
\end{tabular}

Pengumpulan data dilakukan dengan metode observasi dan wawancara singkat terhadap katering yang berada di Desa Banguntapan, Kabupaten Bantul. Data kesehatan lingkungan, kesehatan dan keselamatan para pekerja katering kemudian disampaikan pada saat musyawarah dengan pemilik catering guna menetapkan permasalahan dan langkah solusi yang akan dijadikan kegiatan pengabdian kepada masyarakat. Secara persuasif pengabdi meyakinkan pemilik katering tentang kontribusinya yang penting dalam menegakkan keselamatan dan kesehatan pekerja. Setelah pemilik katering menyetujui untuk dilakukan penyuluhan singkat maka disepakati waktu pelaksanaan pengabdian pada tanggal 20 - 21 Februari 2020, namun hanya tiga katering yang bersedia. Pemilik katering lainnya tidak bersedia dengan alasan sibuk karena banyak pesanan, dan sedang merehabilitasi gedung.

Pengabdi menggunakan media poster sebagai alat bantu penyuluhan, dilanjutkan dengan diskusi dan tanya jawab. Materi yang diberikan berkaitan dengan konsep ergonomi yaitu manual material handling untuk mencegah musculoskeletal disorders dan low back pain. Metode penyuluhan dengan poster ini mudah diterapkan serta tidak memakan waktu dan biaya yang banyak karena sulitnya mencari waktu disela kesibukan pekerja katering. Pengusul melakukan persiapan administratif seperti persiapan poster. Pada akhir penyuluhan, poster dipasangkan pada tempat kerja untuk memudahkan pekerja mengingat materi pasca penyuluhan. 


\section{Hasil dan Pembahasan}

Dari hasil observasi dan wawancara dengan pengelola katering, ditemukan beberapa permasalahan kesehatan kerja di katering seperti terlihat pada tabel 2:

Tabel 2. Identifikasi Masalah Kesehatan Kerja di 5 Katering

\begin{tabular}{ccccc}
\hline \multirow{2}{*}{ Bahaya } & \multicolumn{2}{c}{ Ya } & \multicolumn{2}{c}{ Tidak } \\
\cline { 2 - 5 } & $\mathrm{F}$ & $\%$ & $\mathrm{~F}$ & $\%$ \\
\hline Fisik & 5 & $100 \%$ & 0 & $0 \%$ \\
Kimia & 2 & $40 \%$ & 3 & $60 \%$ \\
Biologi & 5 & $100 \%$ & 0 & $0 \%$ \\
Ergonomi & 5 & $100 \%$ & 0 & $0 \%$ \\
Psiko Sosial & 4 & $80 \%$ & 1 & $20 \%$ \\
Kecelakaan Kerja & 5 & $100 \%$ & 0 & $0 \%$ \\
\hline
\end{tabular}

\begin{tabular}{ccccc}
\hline \multirow{2}{*}{ Masalah Kes } & \multicolumn{2}{c}{ Ya } & \multicolumn{2}{c}{ Tidak } \\
\cline { 2 - 5 } & $\mathrm{F}$ & $\%$ & $\mathrm{~F}$ & $\%$ \\
\hline Batuk & 0 & $0 \%$ & 5 & $100 \%$ \\
Sesak Napas & 0 & $0 \%$ & 5 & $100 \%$ \\
Sakit Kepala & 0 & $0 \%$ & 5 & $100 \%$ \\
Pegal Pegal & 3 & $60 \%$ & 2 & $40 \%$ \\
Sakit Mata & 0 & $0 \%$ & 5 & $100 \%$ \\
Diare & 0 & $0 \%$ & 5 & $100 \%$ \\
\hline
\end{tabular}

Berdasarkan hasil identifikasi masalah kesehatan pekerja tidak ditemukan keluhan batuk, sesak nafas, sakit kepala, sakit mata dan diare pada pekerja catering. Keluhan yang sering diutarakan oleh karyawan katering adalah pegal-pegal yaitu sebanyak $60 \%$. Sebagian besar pekerja belum berobat ke rumah sakit terkait dengan keluhan ini dan tidak terdapat pemeriksaan kesehatan secara berkala di tempat kerja. Pegal-pegal terjadi karena kelima usaha jasa boga tidak memiliki batasan jam kerja sehingga pekerja mengalami kelelahan. Dari hasil observasi, pekerja jasa boga juga tidak memperhatikan postur tubuh yang benar saat melakukan aktivitas persiapan, pengolahan dan pendistribusian makanan. Hasil identifikasi kondisi lingkungan berdasarkan observasi adalah seperti pada tabel 3.

Tabel 3. Identifikasi Masalah Berdasarkan Kondisi Lingkungan dan Proses Kerja Kegiatan di Katering

\begin{tabular}{ccccc}
\hline \multirow{2}{*}{ Kondisi Lingkungan } & \multicolumn{2}{c}{ Baik } & \multicolumn{2}{c}{ Tidak Baik } \\
\cline { 2 - 5 } & $\mathrm{F}$ & $\%$ & $\mathrm{~F}$ & $\%$ \\
\hline Bangunan & 5 & $100 \%$ & 0 & $0 \%$ \\
Ventilasi & 4 & $80 \%$ & 1 & $20 \%$ \\
Lantai & 5 & $100 \%$ & 0 & $0 \%$ \\
Cahaya & 5 & $100 \%$ & 0 & $0 \%$ \\
Suhu Udara & 5 & $100 \%$ & 0 & $20 \%$ \\
Pembuangan Limbah & 4 & $80 \%$ & 1 & $0 \%$ \\
\hline
\end{tabular}

\begin{tabular}{ccccc}
\hline \multirow{2}{*}{ Kegiatan } & \multicolumn{2}{c}{ Ya } & \multicolumn{2}{c}{ Tidak } \\
\cline { 2 - 5 } & $\mathrm{F}$ & $\%$ & $\mathrm{~F}$ & $\%$ \\
\hline Memakai Panas & 5 & $100 \%$ & 0 & $0 \%$ \\
Produksi Panas & 5 & $100 \%$ & 0 & $0 \%$ \\
Bising & 0 & $0 \%$ & 5 & $100 \%$ \\
Bergetar & 0 & $0 \%$ & 5 & $100 \%$ \\
Memotong & 3 & $60 \%$ & 2 & $40 \%$ \\
Mengaduk & 4 & $80 \%$ & 1 & $20 \%$ \\
Mengelas & 0 & $0 \%$ & 5 & $100 \%$ \\
Menggiling & 3 & $60 \%$ & 2 & $40 \%$ \\
Mengecat & 0 & $0 \%$ & 5 & $100 \%$ \\
Menjahit & 0 & $0 \%$ & 5 & $100 \%$ \\
Mengasah & 2 & $40 \%$ & 3 & $60 \%$ \\
\hline
\end{tabular}

Sumber : Data primer (2020)

Berdasarkan hasil identifikasi masalah kondisi lingkungan pekerja ditemukan semua katering tidak memiliki kondisi lingkungan yang sesuai standar. Dari 5 usaha jasa boga terdapat satu jasa boga yang kurang baik ventilasinya yaitu katering SPW. Pada katering SPW ukuran ventilasi sangat kecil. Selain itu, katering SPW juga tidak memiliki cerobong asap. Tempat produksi berada di ruang garasi yang memiliki rolling door. Pada saat produksi rollingdoor akan dibuka sehingga asap dapat keluar. Terdapat usaha jasa boga yang pembuangan limbahnya belum baik yaitu Katering M. Pada katering M limbah dibuang melalui saluran yang mengarah ke sungai. Standar pencahayaan dapur yaitu 300 lux (BSN, 2001). Hanya satu usaha jasa boga yang pencahayaannya memenuhi 
standar yaitu katering N sebesar 325,7 lux. Sedangkan katering lain belum memenuhi standar yaitu katering B tingkat pencahayaannya 109,3 lux, katering SPW tingkat pencahayaannya 31,2 lux, katering M tingkat pencahayaannya 39,3 lux.

Berdasarkan hasil identifikasi masalah proses bekerja terdapat masalah yang berisiko yang membahayakan pekerja pada saat bekerja. Semua katering yang dikunjungi pada saat community diagnosis memiliki proses kerja yang memproduksi panas, melakukan aktivitas memotong, mengaduk, menggiling, mengasah, memiliki alat kerja tumpul dan tajam, tidak bergetar, tidak berputar, dan beberapa bagian menggunakan mesin. Umumnya pekerja bekerja lebih dari 8 jam/hari atau lebih $40 \mathrm{jam} / \mathrm{minggu}$. Hari Sabtu atau Minggu pekerja sering lembur. Beberapa katering memberi jatah makan 1 hari sekali terhadap pekerja dan menyediakan air minum, serta tempat cuci tangan. Semua pekerja katering hanya memiliki APD celemek, dan beberapa menggunakan sarung tangan, tetapi tidak menggunakan masker, sepatu, penutup telinga dan kacamata kerja. Di tempat kerja terdapat pekerja perempuan tetapi tidak terlihat disediakan tempat laktasi dan tidak ada kegiatan olahraga. Hasil observasi, tersedia kipas angin dan penghisap debu. Halaman bersih, ada tempat sampah, sampah diambil oleh petugas, air limbah dibuang ke saluran tertentu. Ada beberapa karyawan yang merokok. Berdasarkan pengamatan dan wawancara singkat, bahaya kesehatan dan keselamatan kerja di usaha katering yaitu fisik (factor pencahayaan, suhu udara, api sebagai sumber panas), kimia (asap dan debu), ergonomik (angkat-angkut, sikap kerja), psikososial (stress kerja) dan kecelakaan kerja (gas, benda tajam dan tumpul. Selain itu juga pekerja pada kelima katering tersebut banyak melakukan proses kerja dengan mengangkat peralatan, bahan makanan dan makanan dengan kapasitas besar secara manual dengan tidak memperhatikan postur tubuh yang benar. Tabel 4 menunjukkan perilaku pekerja dalam penggunakan Alat Pelindung Diri (APD).

Tabel 4. Identifikasi risiko berdasarkan perilaku pekerja

\begin{tabular}{clcccc}
\hline \multirow{2}{*}{ No. } & \multicolumn{2}{|}{ Jenis APD } & \multicolumn{2}{c}{ Ya } & \multicolumn{2}{c}{ Tidak } \\
\cline { 2 - 6 } & & Frekuensi & Persentase & Frekuensi & Persentase \\
\hline 1. & Sarung Tangan & 4 & $80 \%$ & 1 & $20 \%$ \\
2. & Masker & 2 & $0 \%$ & 3 & $60 \%$ \\
3. & Baju Pelindung & 2 & $40 \%$ & 3 & $60 \%$ \\
4. & Sepatu & 2 & $40 \%$ & 3 & $60 \%$ \\
5. & Penutup Telinga & 0 & $0 \%$ & 5 & $100 \%$ \\
6. & Kacamata Kerja & 0 & $0 \%$ & 5 & $100 \%$ \\
\hline
\end{tabular}

Hasil identifikasi masalah berdasarkan perilaku pekerja, semua pekerja di usaha katering belum maksimal dalam menggunakan alat pelindung diri. Pekerja pada katering B tidak menggunakan APD baik sarung tangan, baju pelindung, masker, sepatu, penutup telinga maupun kacamata kerja. Pekerja pada katering $M$ hanya menggunakan sarung tangan dan masker, tidak menggunakan baju pelindung, sepatu, penutup telinga dan kacamata kerja. Pekerja pada katering $\mathrm{N}$ hanya memakai sarung tangan, masker, baju pelindung dan sepatu, tidak menggunakan penutup telinga kacamata kerja. Pekerja pada katering SPW hanya memakai sarung tangan dan sepatu, tidak menggunakan baju pelindung, masker, penutup telinga dan kacamata kerja. Pekerja pada katering RI hanya memakai sarung tangan dan baju pelindung, tidak menggunakan masker, sepatu, penutup telinga dan kacamata kerja.Standar suhu yang baik yaitu $22-30^{\circ} \mathrm{C}$ (Kepmenkes, 2004). Kelima usaha jasa boga tidak memenuhi standar suhu yang ditetapkan. Berdasarkan pengukuran, katering $\mathrm{N}$ memiliki suhu $31,6^{\circ} \mathrm{C}$, katering $\mathrm{M}$ memiliki suhu $33,7^{\circ} \mathrm{C}$, katering $\mathrm{B}$ memiliki suhu $30,8{ }^{\circ} \mathrm{C}$, katering SPW memiliki suhu $31,2^{\circ} \mathrm{C}$.

Sesuai hasil musyawarah dengan pemilik catering, pengabdian kepada masyarakat dilaksanakan berupa penyuluhan dengan menggunakan poster. Topik penyuluhan yang disepakati sesuai dengan permasalahan kebanyakan pekerja catering yaitu penyuluhan tentang ergonomi sebagai upaya preventif keluhan pegal-pegal yang sering dirasakan oleh pekerja. Pengukuran hasil 
penyuluhan tidak dapat dilakukan secara kuantitatif (tidak dilakukan pre dan post test) karena pemilik katering tidak bersedia jika pengabdi banyak mengambil waktu pekerjanya.

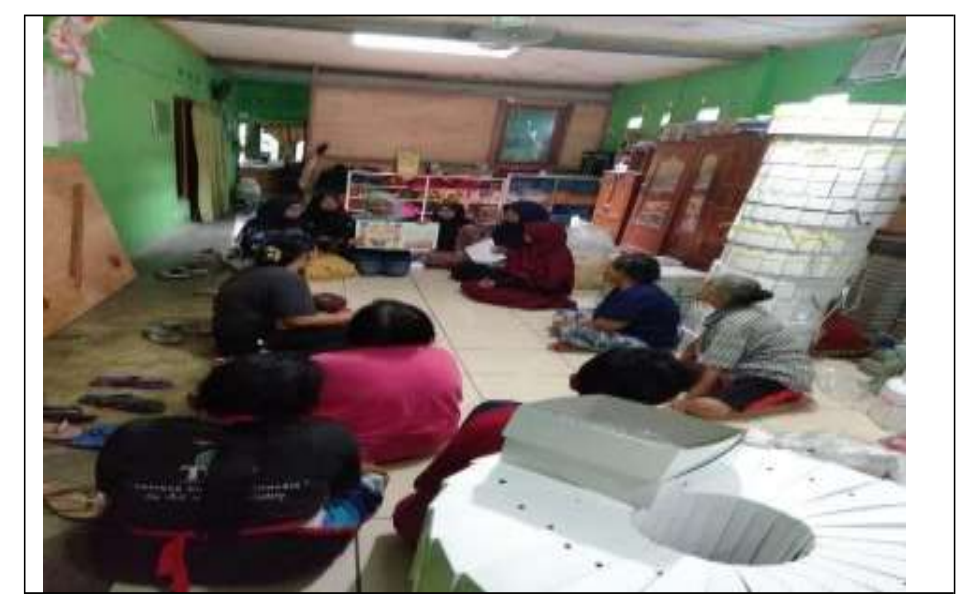

Gambar 1 Penyuluhan dan diskusi dengan pekerja katering

Pada saat kegiatan intervensi dilaksanakan, pengelola dan pekerja katering hadir dan berpartisipasi dengan cukup antusias memberi perhatian pada saat materi disampaikan. Hal ini dapat dilihat dari respons mereka pada saat kegiatan berlangsung dimana terjadi komunikasi dua arah. Para pekerja aktif memberikan tanggapan mereka mengenai materi yang disampaikan. Adapun materi penyuluhan tentang faktor risiko musculoskeletal disorders salah satunya low back pain (LBP) atau sakit pinggang bawah dan proses terjadinya, serta pelatihan mengenai teknik pengangkatan beban yang benar sehingga tidak menimbulkan musculoskeletal disorders. Pada saat diskusi, pekerja menyampaikan salah satu contoh faktor risiko ergonomik yang banyak ditemui di lingkungan kerja katering adalah posisi sikap saat memotong sayuran dengan kursi yang kecil (dingklik) dengan leher menunduk dalam waktu yang lama, posisi saat mengangkat secara manual alat memasak (wajan) besar berisi makanan matang dari tungku, posisi inilah yang dapat memungkinkan pekerja mengalami gangguan kesehatan terutama pada bagian sendi yang dapat mempengaruhi postur dan kesehatan pekerja di katering tersebut.

Aktivitas berulang, peregangan otot yang sangat berlebihan, sikap kerja yang alamiah merupakan faktor-faktor yang dapat mengakibatkan terjadinya keluhan otot (Shankar et al., 2015). Musculoskeletal desease sendiri merupakan kasus penyakit kesehatan kerja yang sering terjadi dan memunculkan absenteisme tinggi di tempat kerja. Para pekerja dengan risiko tinggi Low Back Pain adalah pekerja yang bekerja dengan postur tubuh janggal, melakukan aktivitas pengangkatan beban dengan frekuensi dan durasi tinggi (Abdullah et al., 2014; Nagasu et al., 2007; Tomita et al., 2013). Pekerja juga disarankan menggunakan peralatan seperti pisau dengan pegangan yang ergonomis dan tajam untuk mengurangi kekuatan yang dibutuhkan oleh pengguna saat memotong bahan makanan. Pekerja perlu mempertimbangkan kemampuan fisiknya untuk melakukan tugas tertentu, dengan memperhatikan: usia dan ukuran badan seorang individu; kecepatan dan intensitas pekerjaan - jika kecepatannya terlalu tinggi, ini dapat meningkatkan risiko cedera melalui kelelahan dan menimbulkan stres; perlu perhatian khusus terhadap pekerja yang memiliki masalah kesehatan atau kelemahan fisik; seperti pekerja hamil memiliki peningkatan risiko masalah postur tubuh, keterbatasan kemampuan, kelelahan dan rentan stres akibat panas (Hospitality and catering Industry Liaison Forum, 2017). Perempuan lebih berisiko mengalami keluhan musculoskeletal dibandingkan laki-laki, apalagi melakukan pengangkatan benda berat pada saat kehamilan, lebih berisiko mengalami low back pain dan musculoskeletal disorders (Almoallim et al., 2014; Tarwaka, 2004).

Risiko yang terkait dengan penyimpanan adalah: pengangkatan barang berat; membungkuk ke rak yang lebih tinggi atau lebih rendah. Risiko dapat dikurangi dengan sejumlah cara misalnya membuat area penyimpanan yang sedekat mungkin dengan area kerja untuk mengurangi jarak 
angkut (Hospitality and catering Industry Liaison Forum, 2017). Pengangkatan adalah pekerjaan yang paling biasa yang berhubungan dengan nyeri punggung bawah (Abdullah et al., 2014). Banyak dari cedera ini tidak disebabkan oleh kejadian seketika tetapi terbentuk melalui kurun waktu. Sebagai akibatnya, jumlah berat yang diangkat pada saat terjadi cedera mungkin hanya sedikit mempengaruhi terjadinya cedera. Cedera disebabkan oleh pengangkatan yang berulang, seperti membungkuk dan mengangkat objek keluar dari suatu tempat dalam beberapa jam setiap hari. Cedera punggung bawah dapat juga disebabkan dari pekerjaan penanganan bahan secara manual lainnya, seperti menurunkan, mendorong, menarik, dan membawa (Benynda, 2016).

Tujuan diaplikasikannya aspek ergonomi di tempat kerja yakni dapat mengurangi stres kerja pada fisik secara berlebihan, dapat meminimalisir kemungkinan terjadinya gangguan musculoskeletal dan gangguan kesehatan lainnya hingga tercipta kondisi tempat kerja yang aman dan nyaman demi kenaikan produktivitas di tempat kerja (Tarwaka, 2004). Kegiatan edukasi tentang pengangkatan material secara manual ini berjalan dengan lancar.Ppengelola dan para pekerja secara aktif merespons diskusi dan dapat mempraktikkan secara langsung pencegahan keluhan musculoskeletal pada pekerja di katering. Upaya ini dilakukan untuk meningkatkan pengetahuan dan kesadaran dalam mewujudkan konsep lingkungan kerja yang ergonomis. Diharapkan dengan adanya kegiatan ini pihak katering dapat menerapkan solusi dari permasalahan yang ada di tempat kerja mereka.

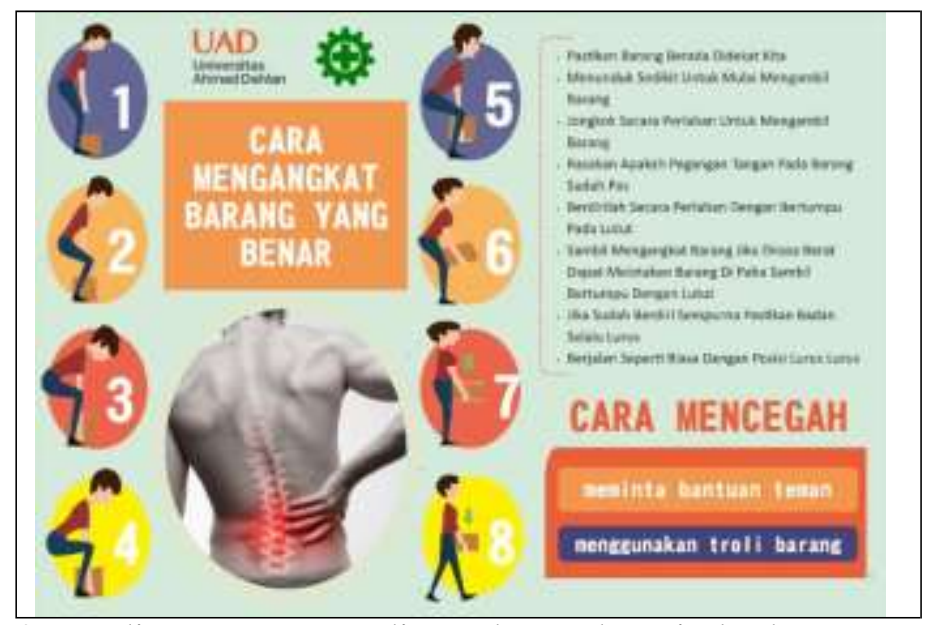

Gambar 2. Media poster yang digunakan sebagai alat bantu penyuluhan

\section{Kesimpulan dan Saran}

Pelaksanaan kegiatan pengabdian berjalan dengan lancar, walau dilakukan dengan metode penyuluhan singkat yang memanfaatkan poster sebagai media. Kegiatan intervensi berisi serangkaian kegiatan berupa penyampaian materi terkait masalah pengangkatan beban secara aman, diskusi tanya jawab, serta memberikan pelatihan tentang teknik manual material handling yang berisi cara mengangkat barang yang benar, diakhiri dengan penempelan poster di lokasi katering. Setelah kegiatan ini diharapkan pemilik dan para pekerja katering dapat menerapkan lingkungan kerja yang lebih ergonomis untuk mencegah penyakit akibat kerja khususnya Low Back Pain (LBP). Adanya kegiatan promosi kesehatan di usaha katering di wilayah kerja Puskesmas Banguntapan III ini diharapkan dapat berdampak pada peningkatan pengetahuan para pekerja katering mengenai teknik manual handling yang merupakan salah satu cara kerja yang aman sehingga dapat mencegah pekerja dari penyakit akibat kerja berupa gangguan otot.

Disarankan agar pemilik katering bersedia melakukan pemeriksaan kesehatan secara berkala terhadap pekerja katering sebagai upaya deteksi dini Penyakit Akibat Kerja (PAK), melakukan olah raga bersama pada hari tertentu untuk mengembalikan kebugaran karena sering melakukan posisi sikap kerja yang salah saat memasak, menyediakan peralatan kerja seperti alat potong dan alat angkat-angkut yang ergonomis. Kepada pekerja diharapkan dapat menggunakan alat bantu 
untuk membantu pekerjaan mengangkat barang yang berat. Pengabdi lainnya diharapkan dapat memberi pelatihan melakukan identifikasi bahaya, penilaian risiko dan melakukan upaya pengendalian risiko mengangkat beban, deteksi dini dan pencatatan dan pelaporan bahaya dan risiko di usaha katering karena waktu yang cukup singkat tidak memungkin pengabdi memberikan materi pelatihan yang komprehensif.

\section{Daftar Pustaka}

Abdullah, H., Susilo, C. B., \& Sumekar, A. (2014). The relationship between work attittude and the heavy load with low back pain in the carrying laborer in the traditional market Beringharjo Yogyakarta. Jurnal Kesehatan Masyarakat, 7(2), 283-290. https://doi.org/ISSN 1858-1196 Agusdianti, L. N., Sudirman, P. L., \& Muliarta, I. M. (2017). Edukasi ergonomi menurunkan keluhan muskuloskeletal dan memperbaiki konsistensi postur tubuh pada mahasiswa PSPDG Universitas Udayana. Bali Dental Journal, 1(2), 47-53.

AJ, E., Jellema, P., AWM, W., Wensing, M., Mw, van T., \& Grol, R. (2011). Individual patient education for low back pain (Review). In Cochran Database of Systematic Review. https://doi.org/10.1002/14651858.CD004057.pub3.

Almoallim, H., Alwafi, S., Albazli, K., Alotaibi, M., \& Bazuhair, T. (2014). A Simple Approach of Low Back Pain. International Journal of Clinical Medicine, 05(17), 1087-1098. https://doi.org/10.4236/ijcm.2014.517139

Benynda, T. (2016). Hubungan cara kerja angkat angkut dengan keluhan Low Back Pain pada porter di pasar Tanah Abang Blok A Jakarta Pusat. Jurnal Kesehatan Masyarakat.

Budiman, Nurhayati, E., \& Sakinah, R. K. (2017). Analisis potensi bahaya pada pekerja industri makanan skala kecil di Kabupaten Bandung tahun 2017. Prosiding SNaPP2017 Kesehatan, 227-233.

Hospitality and catering Industry Liaison Forum. (2017). Preventing manual handling injuries to catering staff. In HSE Catering Information Sheet no.24 (3rd ed., pp. 1-6). Retrieved from https://www.hse.gov.uk/catering/msd.htm

Nagasu, M., Tomita, S., \& Miyagi, S. (2007). Prevalence and risk factors for low back pain among professional cooks working lunch services. BMC Public Health, 7(July), 1-10. https://doi.org/10.1186/1471-2458-7-171

Nurhafizhoh, F. H. (2019). Perbedaan Keluhan Low Back Pain pada Perawat. Higeia Journal of Public Health Research and Development, 3(4), 534-544. https://doi.org//10.15294

Pratiwi, H. M., Widjasena, B., \& Suroto. (2015). Analisis Praktik Menggendong pada Buruh Gendong Wanita di Pasar Induk Buah pada Sayur Giwangan Kota Yogyakarta. Jurnal Kesehatan Masyarakat Universitas Diponegoro, 3(2), 147-157.

Rizqiyah, M., Universitas, A., \& Malang, N. (2020). Pengaruh Sikap Manual Material Handling Siswa Terhadap Keluhan Musculoskeletal Disorders. 2(2), 130-136.

safetysign.co.id. (2018). Cegah Cedera, Pekerja Harus Paham Panduan Manual Material Handling (MMH) Yang Benar! Retrieved https://www.safetysign.co.id/news/369/Cegah-Cedera-Pekerja-Harus-Paham-PanduanManual-Material-Handling-MMH-yang-Benar

Sari, D. C., Ismaningsih, Zein, R. H., \& Hayati, W. (2019). Edukasi Kasus Low Back Pain Myogenik siswa dengan Modalitas Infrareddan William Flexion Exercise. Jurnal Pengabdian Masyarakat Multidisiplin, 3(1), 15-18. Retrieved from http://jurnal.univrab.ac.id/index.php/jpm/article/view/688/480

Sekaaram, V., \& Ani, L. S. (2017). Prevalensi musculoskeletal disorders ( MSDs ) pada pengemudi angkutan umum di terminal mengwi , kabupaten Badung-Bali. Intisari Sains Medis, 8(2), 118-124. https://doi.org/10.1556/ism.v8i2.125

Shankar, S., Shanmugam, M., \& Srinivasan, J. (2015). Workplace factors and prevalence of low back pain among male commercial kitchen workers. Journal of Back and Musculoskeletal 
Rehabilitation, 28(3), 481-488. https://doi.org/10.3233/BMR-140544

Sholihah, Q., Satria, A., Alim, A., \& Fauzia, R. (2016). Ergonomics Awareness as Efforts to Increase Knowledge and Prevention of Musculoskeletal Disorders on Fishermen. Aquatic Procedia, 7, 187-194. https://doi.org/10.1016/j.aqpro.2016.07.026

Suma'mur. (1982). Ergonomi untuk Produktivitas Kerja. Jakarta: Yayasan Swabhawa Karya.

Tania, C. (2020). Training exercise on complaints work-related musculoskeletal disorders (WMSDs) in the administration employees of BPOM Lampung. Wellness and Healthy Magazine, 2(1), 95-104.

Tarwaka. (2004). Ergonomi Untuk Keselamatan Kesehatan Kerja dan Produktivitas. Surakarta: Uniba Press.

Tarwaka. (2014). Ergonomi Industri Dasar-dasar Pengetahuan Ergonomi dan Aplikasi di Tempat Kerja. Surakarta: Harapan Press.

Tomita, S., Matsuzuki, H., Muto, S., Hamamatsu, S., Hospital, G., \& Ayabe, M. (2013). Risk Factors for Frequent Work-related Burn and Cut Injuries and Low Back Pain among Commercial Kitchen Workers in Japan. Industrial Health, 51(December), 297-306. https://doi.org/10.2486/indhealth.2012-0134

TSO London. (2020). Manual Handling at Work: a Brief Guide. Retrieved from https://www.hse.gov.uk/msd/manual-handling/training.htm

Wahab, A. (2019). Faktor-faktor yang Berhubungan dengan Keluhan Nyeri Punggung Bawah (Low Back Pain) pada Nelayan di Desa Batu Karas Kecamatan Cijulang Pangandaran. Biomedika, Jurnal UMS, 11(1), 35-40. https://doi.org/10.23917/biomedika.v11i1.7599

Wijayanti, F., Oktafany, Ramadhian, M. R., Saftarina, F., \& Cania, E. (2019). Kejadian Low Back Pain ( LBP ) pada penjahit konveksi di Kelurahan Way Halim Kota Bandar Lampung. Medula, 8(2), 82-88.

Xu, Y.-W., Cheng, A. S., \& Li-tsang, C. W. P. (2013). Prevalence and risk factors of work-related musculoskeletal disorders in the catering industry: A systematic review. Work, 44, 107116. https://doi.org/10.3233/WOR-2012-1375 